\title{
Prognostic DNA methylation markers for sporadic colorectal cancer: a systematic review
}

Muriel X. G. Draht ${ }^{1}$, Danny Goudkade ${ }^{1}$, Alexander Koch¹, Heike I. Grabsch ${ }^{1,2}$, Matty P. Weijenberg ${ }^{3}$, Manon van Engeland ${ }^{1}$, Veerle Melotte ${ }^{1,4}$ and Kim M. Smits ${ }^{1 *}$

\begin{abstract}
Background: Biomarkers that can predict the prognosis of colorectal cancer (CRC) patients and that can stratify high-risk early stage patients from low-risk early stage patients are urgently needed for better management of CRC. During the last decades, a large variety of prognostic DNA methylation markers has been published in the literature. However, to date, none of these markers are used in clinical practice.

Methods: To obtain an overview of the number of published prognostic methylation markers for CRC, the number of markers that was validated independently, and the current level of evidence (LoE), we conducted a systematic review of PubMed, EMBASE, and MEDLINE. In addition, we scored studies based on the REMARK guidelines that were established in order to attain more transparency and complete reporting of prognostic biomarker studies. Eighty-three studies reporting on 123 methylation markers fulfilled the study entry criteria and were scored according to REMARK.

Results: Sixty-three studies investigated single methylation markers, whereas 20 studies reported combinations of methylation markers. We observed substantial variation regarding the reporting of sample sizes and patient characteristics, statistical analyses, and methodology. The median (range) REMARK score for the studies was 10.7 points (4.5 to 17.5) out of a maximum of 20 possible points. The median REMARK score was lower in studies, which reported a $p$ value below 0.05 versus those, which did not $(p=0.005)$. A borderline statistically significant association was observed between the reported $p$ value of the survival analysis and the size of the study population $(p=0.051)$. Only 23 out of 123 markers (17\%) were investigated in two or more study series. For 12 markers, and two multimarker panels, consistent results were reported in two or more study series. For four markers, the current LoE is level II, for all other markers, the LoE is lower.

Conclusion: This systematic review reflects that adequate reporting according to REMARK and validation of prognostic methylation markers is absent in the majority of CRC methylation marker studies. However, this systematic review provides a comprehensive overview of published prognostic methylation markers for CRC and highlights the most promising markers that have been published in the last two decades.
\end{abstract}

Keywords: Biomarker, DNA methylation, Methylation marker, Colorectal cancer, Colon cancer, Prognosis, Survival, Patient outcome, REMARK

\footnotetext{
* Correspondence: kim.smits@maastrichtuniversity.nl

'Department of Pathology, GROW - School for Oncology and Developmental

Biology, Maastricht University Medical Center, Maastricht, The Netherlands

Full list of author information is available at the end of the article
}

(c) The Author(s). 2018 Open Access This article is distributed under the terms of the Creative Commons Attribution 4.0 International License (http://creativecommons.org/licenses/by/4.0/), which permits unrestricted use, distribution, and reproduction in any medium, provided you give appropriate credit to the original author(s) and the source, provide a link to the Creative Commons license, and indicate if changes were made. The Creative Commons Public Domain Dedication waiver (http://creativecommons.org/publicdomain/zero/1.0/) applies to the data made available in this article, unless otherwise stated. 


\section{Background}

Colorectal cancer (CRC) is the third most common form of cancer and accounts for more than 500,000 deaths worldwide each year [1]. Overall, the prognosis of CRC patients is poor with about half of all diagnosed patients dying as a result of recurrence, metastasized disease, or co-morbidities [2]. CRC often develops without symptoms until it has reached an advanced stage. Prognostic markers, which can predict the prognosis of CRC patients and which can stratify high-risk early stage patients from low-risk early stage patients are urgently needed for better management of CRC. Evidence-based results regarding prognostic markers are therefore essential for better patient management.

CRC patient survival is highly dependent on the tumor stage at the time of diagnosis. Therefore, the tumornode-metastasis (TNM) staging system is the gold standard to determine the prognosis of a CRC patient $[3,4]$. In addition, clinical markers, such as poor tumor differentiation, vascular, and/or perineural invasion, as well as molecular markers, such as microsatellite instability (MSI) status and $K R A S$ or $B R A F$ mutation status can be used $[5,6]$. Since in many years, a vast amount of epigenetic biomarkers have been identified and described as promising cancer biomarkers in the scientific literature [7-10]. However, to date, only a few biomarkers have been validated for clinical use $[11,12]$. CRC, in particular, has often been the topic of epigenetic biomarker research, leading to the identification of methylation markers for early detection of CRC, prediction of prognosis, and/or treatment response [8, 13-16]. At the moment some methylation markers for early detection of CRC (such as SEPT9, NDRG4, and BMP3) have been incorporated in the FDA-approved commercial tests, Epi proColon $^{\bullet}$ and Cologuard, respectively [17, 18]. However, for prognostic or predictive purposes, no methylation marker for colon and/or rectal cancer has made the translation to a clinically applicable biomarker. The reasons for the lack of translation of biomarkers, prognostic, or other, into clinical practice, have already been recognized previously, with many different research groups providing possible explanations and/or solutions for these problems, such as poorly selected biospecimens, not-clinically relevant sample series, and underpowered sample series, as well as lack of validation and reproducibility of the biomarker assay [19-24]. In 2005, the REporting recommendations for tumor MARKer prognostic studies (REMARK) guidelines were published in an effort to improve the reporting of biomarker studies and subsequently increase the number of prognostic biomarkers that can be used in clinical practice [25]. Nevertheless, there is evidence that adherence to REMARK is still suboptimal $[26,27]$.
A comprehensive overview of potentially promising prognostic epigenetic biomarkers for CRC is lacking. Furthermore, the current amount of available information only leads to more confusion instead of contributing to answering the question, which biomarker should be further developed for translation. Here, we provide a comprehensive overview of the currently available evidence on prognostic DNA methylation markers for $\mathrm{CRC}$ and review the quality of these studies using the REMARK guidelines as a tool.

\section{Methods \\ Search strategy and study eligibility}

A literature review was performed covering English language articles in PubMed, EMBASE, and MEDLINE until May 2017 using the following search terms: DNA methylation, biomarker, cancer, colon, colorectum, colorectal, survival, patients outcome, prognosis (Additional file 1). Published studies were eligible to be included in our analysis if colon, rectal, or colorectal cancer patient prognosis was analyzed stratifying patients by methylation status of the marker. Only original articles (no reviews, editorials, conference abstracts, etc.) were considered (Fig. 1). Studies were included if overall survival (OS), disease-specific survival (DSS), disease-free survival (DFS), recurrence-free survival (RFS), or any other endpoint were reported and if results were presented as Kaplan-Meier plots, relative risks, or hazard ratios (HRs) with corresponding 95\% confidence intervals $(95 \% \mathrm{CI})$. We did not restrict our search to specific patient characteristics (such as age group, sex, ethnicity, and tumor type). Studies were excluded if the tumor was hereditary; prognosis was not analyzed by one of the abovementioned methods; studies were focusing on the prognostic influence of the $\mathrm{CpG}$ island methylator phenotype (CIMP and microsatellite instability (including MINT loci)), as this has been the topic of multiple systematic reviews of our and other research groups [28-32]; and studies were on methylated miRNAs and LINE-1, as our focus in this review was directed to $\mathrm{CpG}$ islands of protein-coding genes.

\section{Data extraction}

Data extraction was performed by two independent researchers (MD and DG) using a standardized data registration form in which the following items were recorded: marker of study, sample size, cancer type (colon, rectum, or $\mathrm{CRC}$ ), sample type (primary tissue, serum, mucosa, blood, lymph node tissue, peritoneal lavage, or stool), stage (tumor-node-metastasis (TNM) staging, according to editions mentioned in original paper, or Dukes' staging), study design, year of collection of samples, number of patients in survival analyses, 


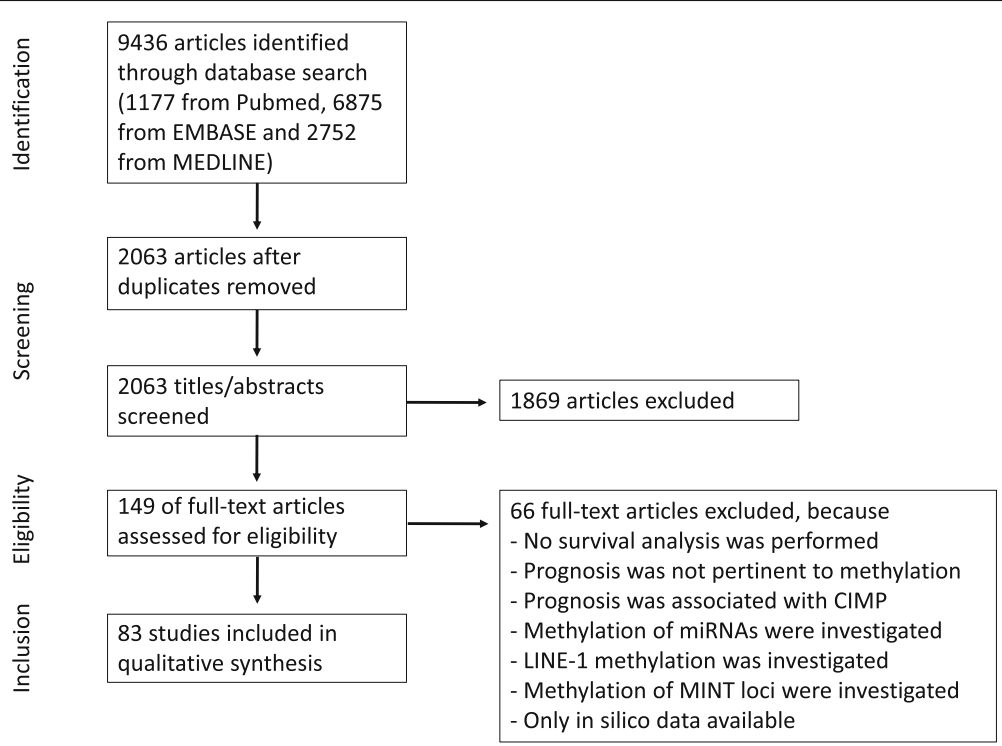

Fig. 1 Flowchart of the study identification process. A total of 83 studies were selected for qualitative assessment

endpoints, subgroup analysis, $p$ value, and hazard ratio (HR) with corresponding confidence interval. This systematic review was conducted according to the Preferred Reporting Items for Systematic Reviews and MetaAnalyses (PRISMA) statement, where applicable [33].

\section{Quality assessment}

Eligible studies were scored (MD and DG) based on the REMARK criteria [34], which summarizes 20 items for good reporting of a prognostic biomarker study (Additional file 2). In case of complete reporting according to the guidelines, a study was given 1 point, in case of incomplete reporting, a study was given 0.5 points, and in case of lack of reporting any aspect of the guideline item, a study was given 0 points. The maximum score was 20 points (all items adequately reported). Interobserver variation of scores was solved by mutual consensus. The risk of potential bias and confounders was analyzed per study using the information obtained with the REMARK scores. If a study obtained $\geq 1.5$ points for REMARK criterion \#2 ("patient characteristics") and \#6 ("sample selection and follow-up"), the risk of selection bias was low. In case of less than 1.5 points, the risk of potential selection bias is increased. Bias regarding the assay method (measurement bias) was assessed similarly using REMARK criteria \#5 ("assay method") and \#11 ("handling of marker values"). The risk of bias regarding outcome assessment (measurement bias) was scored based on REMARK criterion \#7 ("clinical endpoint definition"). In case of complete reporting (score $=1$ ), the risk of bias is low, as compared to partial or lack of reporting, which increases a potential risk of bias. The presence of potential confounding factors was assessed using REMARK criterion \#16 ("multivariable analysis"). In case of 1 point, the risk of confounding factors is lower as compared to studies that did not perform or report a multivariable analysis. In order to investigate whether the REMARK score or the total number of patients included in the survival analysis correlates with the reported significance of the marker ( $p$ value), we performed a regression analysis and determined the Pearson's correlation coefficient $(r)$. We compared the REMARK scores of studies reporting a significant finding versus studies reporting a non-significant finding using a Mann-Whitney test. We used the statistical programming language $R$ (version 3.3.1) to perform all analyses.

\section{Forest plots}

We prepared forest plots for methylation markers that were investigated in two or more study series. If available, we reported HRs for overall and subgroup analysis, such as single TNM stages or mutation status. Univariate HRs were used, unless multivariate HRs were available. If multiple HRs were available, the most adjusted HR was depicted in the plot. In order to give a complete overview, $p$ values are depicted in the forest plot, if only Kaplan-Meier results were available. We used the statistical programming language $R$ (version 3.3.1) to perform all analyses and generate the figures.

\section{Level of evidence}

The level of evidence (LoE) can be determined using an evidence-ranking scheme such as GRADE [35] or the 
OCEBM levels [36] in which level I represents definitive evidence, level IV represents (very) weak evidence, and the remaining levels a degree in between. Even though these rankings do not provide a definitive judgment on the quality of the provided evidence, they do offer a valuable indication. To give an overview of the current evidence on prognostic epigenetic biomarkers in CRC, we classified a LoE to each marker, or marker panel, investigated in two or more independent study series, using a ranking scheme adapted for biomarkers [37] and the OCEBM schemes [36].

\section{Results}

\section{Eligible studies}

We initially identified 2063 studies for potential inclusion using our search strategy (Additional file 1). We excluded 1869 studies mainly because they were either not original studies or not relevant to prognosis or colorectal cancer, colon cancer, or rectal cancer. We checked full-text articles of the remaining 194 studies, of which 66 were excluded, for prognosis was not pertinent to methylation, prognosis was associated with CIMP, methylation of non-protein-coding genes was investigated (miRNAs, LINE-1, MINT loci), or only in silico data were described (Fig. 1). A total of 83 studies were included in this systematic review.

\section{Study characteristics}

Study characteristics are summarized in Additional file 3. Sixty-three $(76 \%)$ studies reported results from single methylation markers, and 20 (24\%) studies included multiple markers. In total, 123 different methylation markers were investigated (Additional file 3). Studies were published between 1999 and 2017. Median (range) sample size was 127 patients (30 to 1105 patients). Seventy-four (89\%) studies investigated CRC, six (7\%) studies investigated colon cancer only, and three (4\%) studies investigated rectal cancer only. Sixty-eight (82\%) studies used formalin-fixed or fresh-frozen primary tissue for biomarker analyses, 10 (12\%) studies used blood (serum or plasma), two (3\%) studies used normal mucosa, one study (1\%) used peritoneal lavage fluid, and in one study (1\%), the tissue used in the analyses was not specified. Thirteen (16\%) studies included patients with the same single TNM (or Dukes) stage, 68 (82\%) studies included patients with two or more disease stages. For two (3\%) studies, the TNM (or Dukes) stage of the included patients was not specified. Eighty-two studies (99\%) used Cox proportional hazard analyses, Kaplan-Meier plots, or both to assess the relation with overall, regression-free, or disease-specific survival. For one study (1\%), the statistical method was not described.

\section{Quality assessment}

We evaluated studies according to the REMARK checklist and assigned a score between 0 and 20 to each study (Additional file 4). The scores ranged from 4.5 points to 17.5 points with a median score of 10.7 (Fig. 2a). Among the 83 studies that were scored according to the REMARK criteria, we observed a large variation in the amount of information given for the specific criterion. For only two criteria (\#1"state marker, objectives, and hypotheses" and \#5 "specify assay details"), complete or partial information was given for all studies. For the other criteria, these numbers ranged from 10\% (\#11 "specify marker values in analyses and discuss cut-off points") to $99 \%$ (\#19 "interpretation of results and study limitations") (Fig. 2b). Full quality scores could only be given for one REMARK criterion (\#1 "state marker, objectives, and hypotheses") for the majority of the studies (98\%). For all other criteria, the percentage of studies obtaining full quality scores ranged from 1\% (\#11 "specify marker values in analyses and discuss cutoff points") to $70 \%$ (\#4 "describe biological material") (Fig. 2b). Almost none of the studies sufficiently addressed how marker values were handled in the analyses or presented cutoffs (10\%). Less than half of the studies provided complete or partial information on candidate markers initially considered for the study (28\%), reported a rationale for sample size (28\%), reported estimated effects with corresponding confidence intervals of the marker and other prognostic variables in the analyses (47\%), or reported further investigations such as checking assumptions of proportional hazards (31\%). A complete overview of the REMARK scores for the different studies per REMARK criterion is presented in Additional file 4. The risk of bias of each included study is summarized in Additional file 5.

Since it is more likely that studies reporting statistically significant results get published [38, 39], we were interested whether there is an association between REMARK score and reported $p$ value and whether inadequately reported studies tend to more frequently report significant results. Although REMARK scores varied between the individual studies, $p$ values $<0.05$ for the association between the methylation marker and prognosis were more often reported in studies with lower REMARK scores, as compared to studies with average to high REMARK scores (Fig. 3a, $p=0.005$ ), although this was not seen in the Pearson's correlation coefficient (Fig. 3b; $r=0.0543, p=0.499)$. Whereas almost half $(46 \%)$ of the 83 selected studies exclusively reported significant results, $24 \%$ of all studies reported nonsignificant methylation marker results and 30\% described statistically significant, as well as nonsignificant results. Often, methylation markers were 


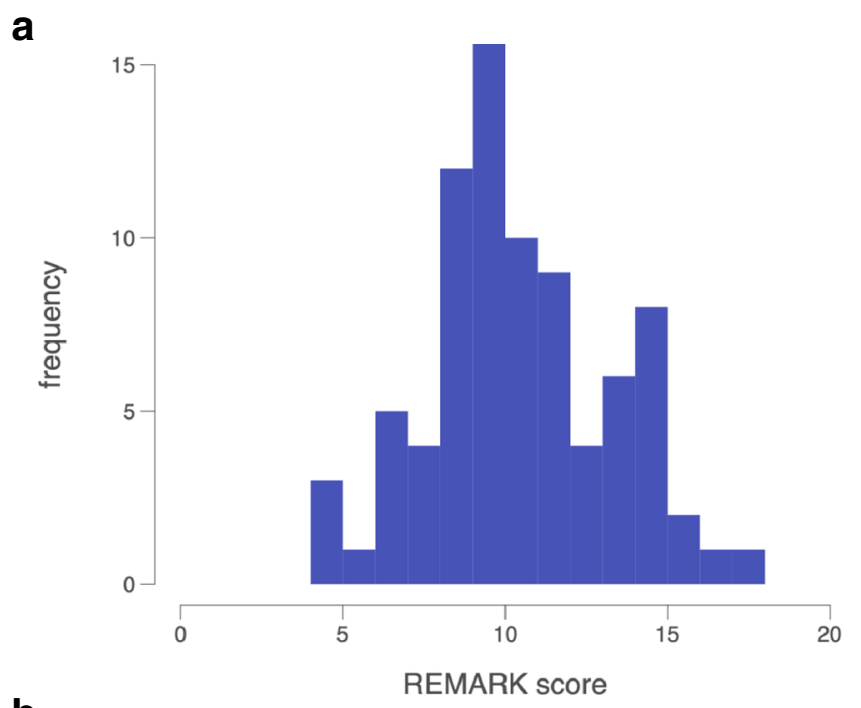

b

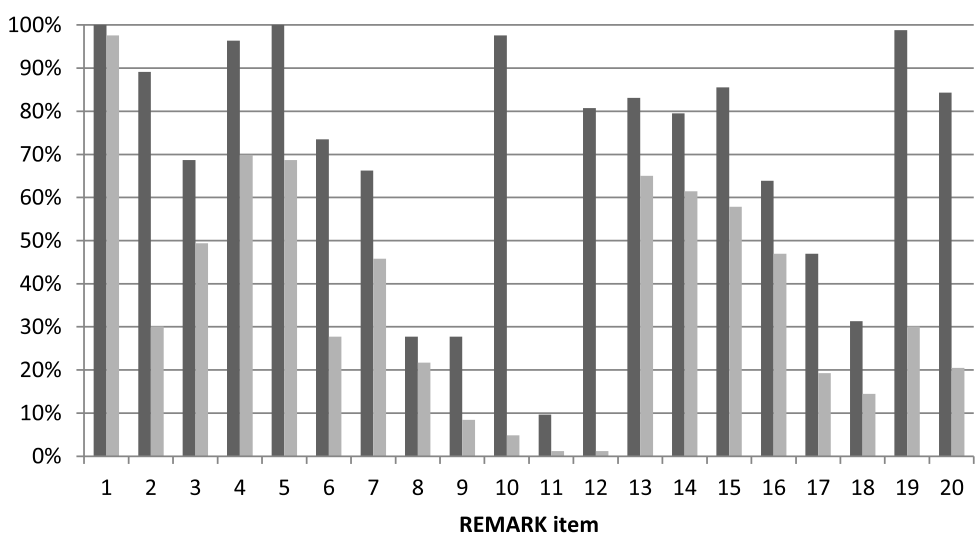

घ completeness of REMARK items $\quad$ \% studies with max. quality scores

Fig. 2 Quality assessment of methylation marker studies. a Histogram depicting the REMARK score distribution for all studies included in the analysis (mean REMARK score $=10.711$, standard deviation $=2.820$ ). $\mathbf{b}$ Histogram showing the completeness of reported REMARK items

reported in small study populations (median $n=$ 127.5), increasing the possibility that reported prognostic effects cannot be validated in other study populations. Therefore, we were interested whether there is an association between the reported $p$ value and the number of patients included in the survival analysis. A borderline statistically significant correlation was observed between the reported $p$ value of the survival analysis and the size of the study population (n) (Fig. 3c; $p=0.051$ ).

\section{Prognostic marker findings}

Additional file 3 shows the impact of methylation markers on prognosis in the included studies [40-122]. The majority of markers were investigated in a single study without any internal or external validation. As unvalidated results are at higher risk to represent chance findings, validation in at least one independent population is needed to draw any conclusion, even preliminary, for these markers. Therefore, we only prepared forest plots for methylation markers that were investigated by two or more studies and/or where internal validation in an independent series was performed (i.e., IGFBP3, CDKN2A (p16), WNT5a, HPP1, RET, TFPA2E, HLTF, EVL, CD109, NRCAM, FLNC, BNIP3, MLH1, MGMT, RASSF1A, CDKN2A (p14), APC, CHFR, SEPT9, and one multimarker panel; Fig. 4).

Overall, studies assessing IGFBP3 methylation showed similar correlations with a poor prognosis in CRC patients. Yi et al. firstly investigated IGFBP3 hypermethylation as a prognostic marker in three different study populations [48]. Although a significant association was found with poorer OS in the two smaller populations $(n=147, n=72$; HR 2.58 95\% CI 1.37-4.87, HR 2.06 95\% CI 1.04-4.09, respectively), no association was 


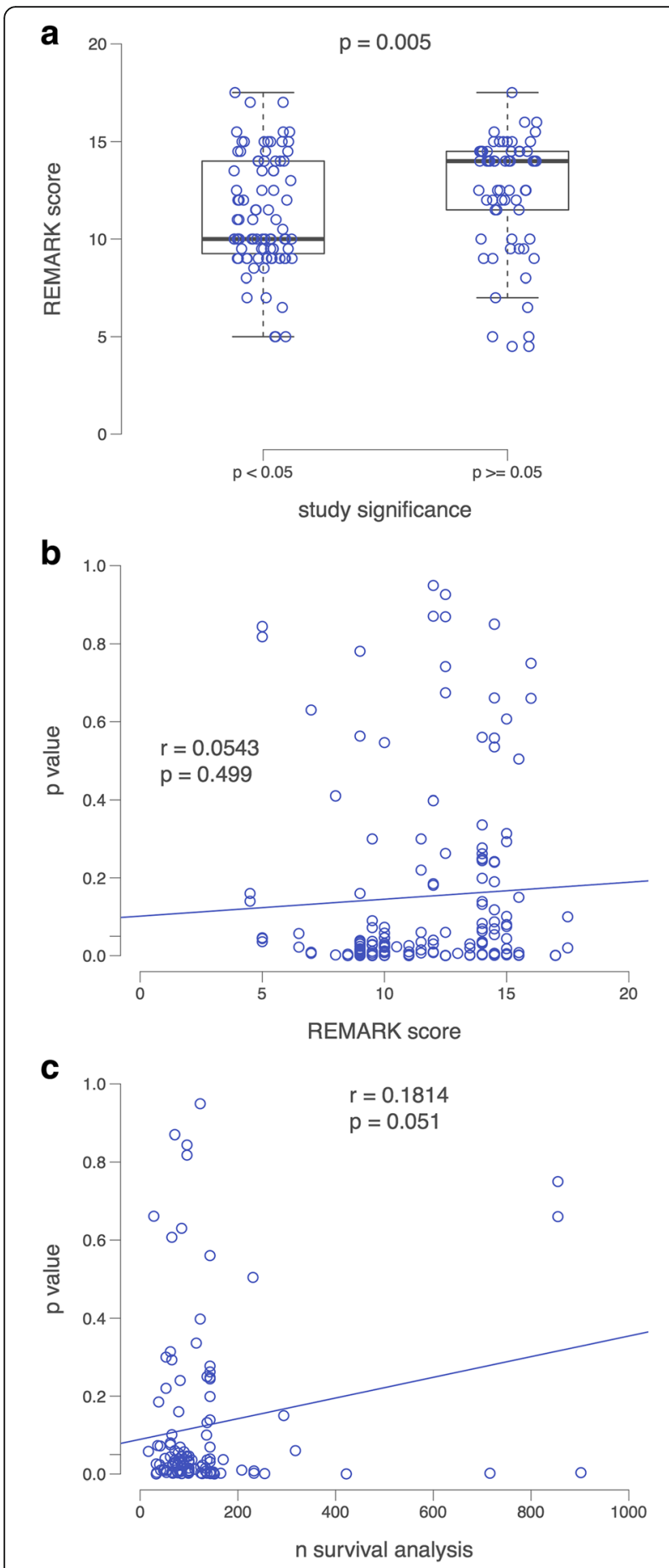

Fig. 3 Association between REMARK score and significance level of studies. a Box plot comparing the REMARK score between studies that reported statistically significant findings versus studies that did not report statistically significant findings (Mann-Whitney test, $p=0.005$ ). $\mathbf{b}$ Dot plot showing that there was, however no significant correlation between the REMARK score and the reported $p$ values (Pearson's correlation coefficient $=0.0543, p$ value $=0.499)$. $\mathbf{c}$ Dot plot depicting that for the reported survival analyses, we found a stronger, but still statistically not significant correlation between the number of patients used and the reported $p$ values (Pearson's correlation coefficient $=0.1814, p$ value $=0.051$ ) found in a cohort of 558 patients (data not shown in original article). In a subgroup analysis, IGFBP3 hypermethylation was found to be a prognostic factor in three independent studies, all focusing on TNM stages II-III, even though every study used a different endpoint (RFS, DFS, and OS) (HR 6.46 95\% CI 1.51-27.70; HR 2.40 95\% CI 1.10-5.25; HR 0.48 95\% CI 0.26-0.87; HR 2.04 95\% CI 1.34-3.09) [48, 89, 90].

CDKN2A (p16) was by far the most often studied biomarker, with ten studies in TNM stage I-IV [53, 57, 59-61, 63-65, 70, 73] and 13 studies in different subgroups $[50-53,55,56,58,62,69,73]$. Only one study in TNM stages I-IV showed a statistically significant association between CDKN2A methylation and outcome (HR 1.66 95\% CI 1.2-2.3) [60]. Studies including subgroup analyses however showed statistically significant associations between $C D K N 2 A$ methylation and a poor prognosis in several different subgroups. The studies by Kohonen-Corish et al., Wettergren et al. 2008, and Esteller et al. 2001 in TNM stages I-III and Dukes' stage A-C patients describe a statistically significant association (HR 2.60 95\% CI 1.20-5.70; HR 2.90 95\% CI 1.30-6.20; HR 3.00 95\% CI 1.10-8.10, respectively) [51, 55, 62], although the study of Sanz-Casla et al. could not confirm this $(p=0.09)$ [53]. The studies of Liang et al. [50], Wettergren et al. [55], Mitomi et al. [58], and Maeda et al. [52], focusing on TNM stage II or Dukes' B patients alone or in a larger subgroup of TNM stages II-IV or Dukes' B-C patients, also show statistically significant associations with a poor prognosis $(p=0.0001$; HR $4.7095 \% \mathrm{CI}$ 1.10-19.50; HR 3.38 95\% CI 1.67-6.84; $p=0.022$, respectively). This could not be confirmed by the study of Cleven et al., which was conducted in TNM stage II, microsatellite stable (MSS), and BRAFwt patients [73]. A significant association with a poor prognosis was also reported for Dukes' C patients with mutated KRAS (HR 2.60 95\% CI 1.20-3.50) [62], but not in another study focusing on Dukes' C patients or TNM stage III, MSS, and BRAFwt patients [73].

Methylation of WNT5a was only studied in one publication. Rawson et al. investigated methylation of WNT5a in two large independent series, showing no association between methylation of WNT5 $a$ and prognosis (HR 1.0 95\% CI 0.6-1.7; HR 0.9 95\% CI 0.6-1.3) [122].

Four studies reported on the association between HPP1 hypermethylation and prognosis with conflicting results [78-81]. In TNM stages I-IV, a statistically significant association was shown with OS (HR 5.10 95\% CI $2.20-11.60$ and Kaplan-Meier $p$ value $<0.0001$ ) $[78,81]$. Subgroup analyses of the studies by Philipp et al. showed a statistically significant association between OS and HPP1 hypermethylation in TNM stage IV only (Kaplan-Meier $p$ value 0.0003 and $<0.0001$, respectively) $[80,81]$. The study by Herbst et al. only showed a 


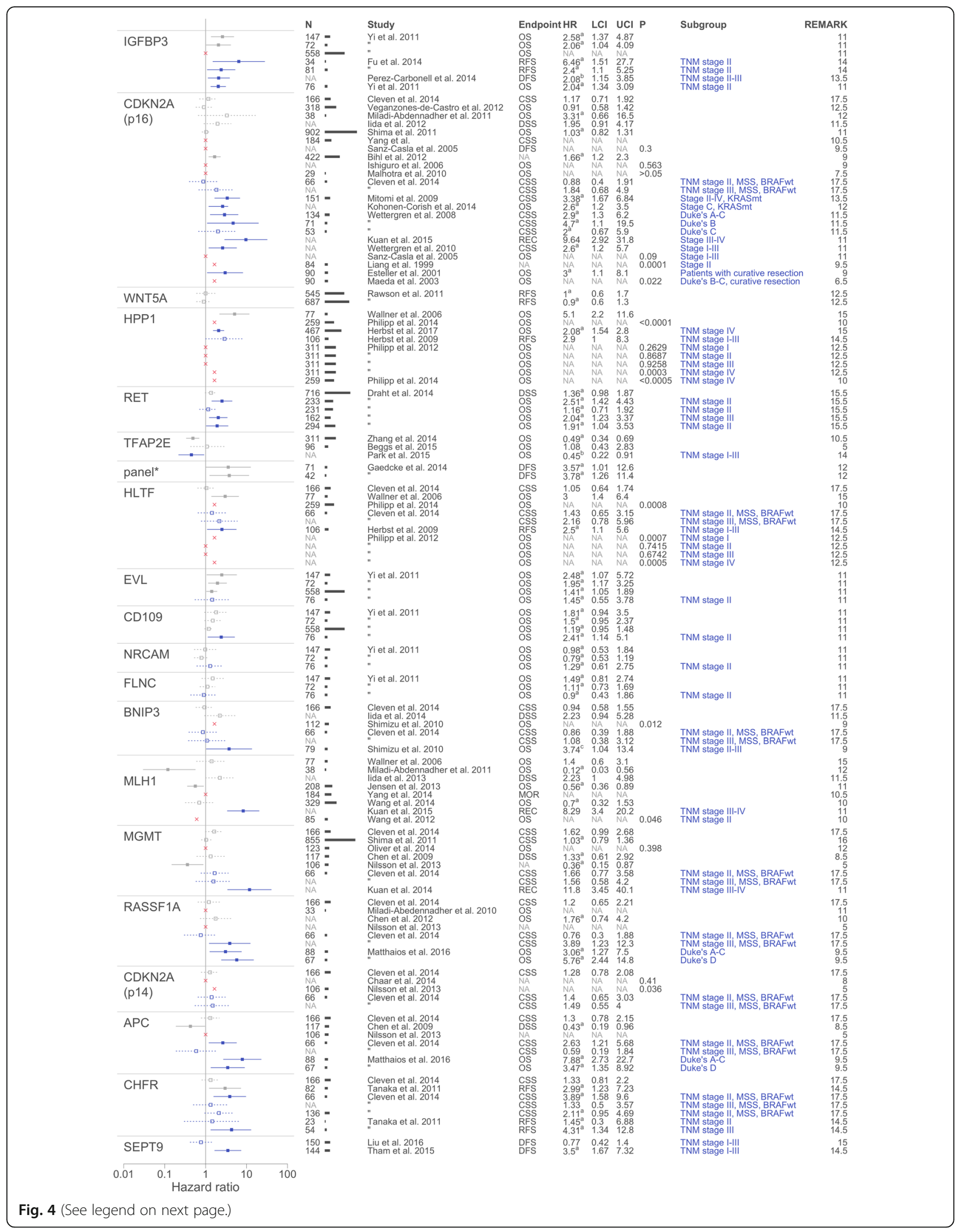


(See figure on previous page.)

Fig. 4 Forest plots of reported methylation markers in colorectal cancer studies. Forest plots were prepared for methylation markers that were reported in two or more publications or study populations. The hazard ratios (HR) are sorted according to the REMARK score. HRs with a statistically significant association are depicted with a solid line; HRs of reported markers with no significant association are depicted with a dotted line; HRs of subgroup analyses are depicted in blue. Univariate HRs and confidence intervals (Cl) are reported unless multivariate HRs were available (a). As for IGFBP3 and TFAP2E the HRs of the study of Perez-Carbonell et al. [90] and Zhang et al. [117], respectively, were both associated with worse survival. For this figure, the HR was reversed for visualization purposes (b). A multivariate HR for BNIP3 methylation was available in the study of Shimizu et al., however was not statistically significant (c)

borderline statistically significant association with RFS (HR 2.90 95\% CI 1.00-8.30) [79]. A recent prospective study by Herbst et al., including 467 TNM stage IV patients, reported a significant poorer OS in patients with HPP1 methylation (HR 1.86 95\% CI 1.37-2.53 for univariate analysis) [82]. After one administration with combination chemotherapy, a multivariate analysis still predicted a poorer outcome for HPP1 methylated patients (HR 2.08 95\% CI 1.54-2.80).

Methylation of $R E T$ was studied in three independent patient series reported in one publication [107]. While there was no association with disease-specific survival in the total population of TNM stage I-IV patients, a significant association with poorer OS was found in two TNM stage II patient series (HR 2.51 95\% CI 1.42-4.43; HR $1.9195 \%$ CI 1.04-3.53) and one TNM stage III patient series (HR 2.04 95\%-CI 1.23-3.37).

Hyper- as well as hypomethylation of TFAP2E was investigated in three studies, of which two studies strikingly reported similar associations between hyper- and hypomethylation and prognosis. The study by Zhang et al. assessed the influence of TFAP2E hypermethylation on prognosis in TNM stage I-IV patients, showing a significant association between TFAP2E hypermethylation and a favorable prognosis (HR 0.49 95\%-CI 0.34-0.69) [117]. A subgroup analysis by Park et al. of TNM stage I-III patients confirmed this association (HR 2.24 95\%-CI 1.10-4.56; HR converted for figure) [118]. In the study of Beggs et al. hypermethylation of TFAP2E was not associated with survival (HR 10.8 95\%-CI 1.08-2.83), however a survival benefit was found in patients with TFAP2E hypomethylation (HR 0.34 95\%-CI 0.12-0.97) [119].

Methylation of $H L T F$ was investigated in five studies with conflicting results. A statistically significant association between HLTF hypermethylation and OS in TNM stage I-IV CRC patients was suggested by Wallner et al. and Philipp et al. (HR 3.0 95\% CI 1.40-6.40 and KaplanMeier $p$ value 0.0008$)[78,81]$, whereas the study of Cleven et al., using CSS as an endpoint, could not confirm this finding (HR 1.05 95\%-CI 0.64-1.74) [73]. Subgroup analyses of TNM stage II and III patients showed no statistically significant association between HLTF hypermethylation and OS or CSS [73, 80]. In TNM stages I and IV, and I-III however, a statistically significant association was observed between HLTF hypermethylation and OS or RFS (Kaplan-Meier $p$-values 0.0007 and 0.0005 , and HR $2.5095 \%$-CI 1.10 5.60 , respectively) $[79,80]$.

Next to IGFBP3, Yi et al. also investigated four other genes (EVL, CD109, NRCAM, and FLNC) in three independent populations [48]. However, only methylation of $E V L$ appeared to have a significant association with worse OS in TNM stage I-IV colon cancer patients (HR 2.48 95\% CI 1.07-5.72; HR 1.95 95\% CI 1.17-3.25; HR $1.4195 \%$ CI 1.05-1.89). Methylation of CD109 was only significantly associated with poorer OS in 76 TNM stage II patients (HR 2.41 95\% CI 1.14-5.1). Yi et al. also investigated combinations of these markers with and without IGFBP3; however, significant results were only reported for the two smaller populations of TNM stage I-IV colon cancer patients $(n=147, n=72)$ [48].

Conflicting results were also found for BNIP3 methylation, which was studied in three different studies $[47,65,73]$. In overall univariate analyses, BNIP3 hypermethylation appeared to be statistically significantly associated with a poorer survival in the study by Shimizu et al. (Kaplan-Meier $p$ value 0.012), whereas the other two studies did not report a statistically significant association with poor prognosis (HR $0.9495 \%$ CI $0.58-1.55$ and HR 2.23 95\% CI 0.94-5.28). Subgroup analyses of BNIP3 methylation showed a statistically significant association with poorer OS in one of two studies (HR 3.74 95\% CI 1.04-13.43) [47] but not in the other (TNM stages II and III, MSS, BRAFwt patients HR 0.86 95\% CI 0.39-1.88, and HR 1.08 95\% CI 0.38-3.12, respectively) [73].

Out of six studies assessing the association between MLH1 methylation and prognosis in TNM stages I-IV, three studies showed statistically significant results; however, two showed a better prognosis (HR 0.12 95\% CI $0.03-0.56$ and HR 0.56 95\% CI $0.36-$ 0.89 , respectively) $[64,83]$, while the study by Iida et al. showed a borderline significant association with a poorer DSS (HR 2.23 95\% CI 1.00-4.98) [65]. The studies by Wallner et al., Yang et al., and Wang et al. showed no association [70, 78, 84]. Subgroup analyses by Kuan et al. and Wang et al. also show these conflicting results with one reporting a statistically significant high recurrence risk (HR 8.29 95\% CI 3.40-20.22) [69], while the other report a better OS when MLH1 is methylated ( $p=0.046)$ [49]. 
For MGMT promoter hypermethylation, four studies showed no association with prognosis in TNM stages I-IV [43, 73, 94, 95], while the study of Nilsson et al. suggested an association between MGMT methylation and a better prognosis (HR 0.36 95\% CI 0.15-0.87) [105]. Subgroup analyses in TNM stages II and III showed no association with $M G M T$ in the study of Cleven et al. [73]. Strikingly, a study by Kuan et al. focused on recurrence and showed a strong association between recurrence and MGMT methylation in TNM stages III-IV (HR 11.83 95\% CI 3.45-40.12) [69].

RASSF1A methylation was studied in five different studies; however, a statistically significant association was only found in TNM stage III patients (HR 3.89 95\% CI 1.23-12.30) [73]. Four studies in TNM stages I-IV and another subgroup analysis on TNM stage II did not show any association between RASSF1 and prognosis [73, 103-105]. Matthaios et al. investigated RASSF1 methylation in Dukes' A-C and in Dukes' D patients, respectively. In both subgroups, RASSF1 methylation was associated with a worse OS (HR 3.06 95\% CI 1.27-7.50; HR 5.76 95\% CI 2.44-14.82, respectively) [106].

For CDKN2A (p14) methylation, the study of Nilsson et al. suggests a worse prognosis in TNM stages I-IV ( $p=0.036)$ [105], while the studies of Cleven et al. and Chaar et al. do not confirm these findings [73, 99]. Subgroup analyses also do not show a statistically significant influence of CDKN2A (p14) methylation on prognosis [73].

Hypermethylation of $A P C$ was reported to be positively associated with survival by Chen et al. (HR 0.426 95\% CI 0.190-0.957) [43]; however, two independent studies did not confirm these results [73, 105]. In contrast, in a subgroup of 66 stage II MSS and BRAF wildtype patients, $A P C$ methylation was associated with worse cancer-specific survival (HR 2.63 95\% CI 1.215.68) [73]. Matthaios et al. investigated $A P C$ methylation in Dukes' A-C and in Dukes' D patients, respectively. In both subgroups, $A P C$ methylation was associated with a worse OS (HR 7.88 95\% CI 2.73-22.73; HR 3.47 95\% CI $1.35-8.92$, respectively) [106].

Methylation of CHFR as a prognostic marker was assessed in only two independent studies. In the study by Tanaka et al., CHFR methylation was associated with poorer RFS in TNM stage I-IV patients (HR 2.99 95\% CI 1.23-7.23) [72]. This was not confirmed by the study of Cleven et al., which reported no association with CSS in TNM stage I-IV patients (HR 1.33 95\% CI 0.81-2.20) [73]. Subgroup analysis for TNM stage II and III patients was done in both studies. The study of Tanaka et al. reported no association between CHFR methylation and RFS in TNM stage II patients (HR 1.45 95\% CI 0.30 6.88), but a significant association between CHFR methylation and RFS in TNM stage III patients (HR 4.31
95\% CI 1.34-12.8) [72]. In the study of Cleven et al. subgroup analyses of TNM stage II, MSS and BRAFwt patients showed a significant association between CHFR methylation and CSS (HR 3.89 95\% CI 1.58-9.60), but results were not validated in an independent patient series. Subgroup analysis of TNM stage III, MSS, and $B R A F \mathrm{wt}$ patients did not show a significant association with prognosis [73].

SEPT9 was assessed as a biomarker in two studies. Liu et al. did not find a statistically significant association between methylation and prognosis in TNM stage I-IV or TNM stage I-III patients [109]. The study of Tham et al. reports an association between SEPT9 methylation and worse OS in TNM stage I-III patients (HR 3.50 95\% CI 1.67-7.32) [108]. Although they appeared to have assessed SEPT9 methylation as a biomarker, the study of Perez-Carbonell did not give any specific information on the outcome of this analysis [90].

For three markers (ID4, MYOD1, and SFRP2) and two marker panels (AXIN2 \& DKK1 and CDKN2A \& $h M L H 1)$, analyses were performed in two or more independent studies or patient populations, but reported results were too limited to construct a forest plot (Additional file 6). Methylation of ID4 was assessed by two studies. Umetani et al. reported a significant association between ID4 methylation in stage I-IV CRC patients and poorer OS (HR 1.82 95\% CI 1.09-3.43) [88], but the study of Tanaka et al. did not confirm this $(p=0.118)$ [72]. MYOD1 was suggested as a prognostic biomarker in the study of Hiranuma et al. (HR 3.16 95\% CI 1.25-8.02) [97], but this was not seen in the study of Shannon et al. ( $p=0.14)$ [96]. Also, for SFRP2 methylation, survival data were only reported in one out of two studies [70, 111]. Tang et al. observed a statistically significant association with OS in stage I-IV CRC patients (HR 3.06 95\% CI 1.12-8.40) [111].

Of 83 included studies, 20 studies assessed the prognostic influence of multimarker panels. Although the same markers were included in several multimarker panels, only three panels were assessed in two or more independent studies or patient populations. For one panel consisting of $M L H 1$ and $C D K N 2 A$, a better prognosis in TNM stage I-IV patients was reported in the study of Veganzones et al. ( $p=0.04)$ [66]. However, in the study by Aoyagi et al., methylation of both genes was associated with worse survival in TNM stage IV patients ( $p=0.03$; Additional file 6) [85]. The study of Gaedcke et al. described a panel of markers (ADAP1, BARHL2, CABLES2, DOT1L, ERAS, ESRG, RNF220, ST6GALNAC5, TAF4, SLC20A2) that was associated with poorer DFS in two independent study series (HR 3.57 95\% CI 1.01-12.55; HR 3.78 95\% CI 1.26-11.37; Fig. 2p) [40]. Kandimalla et al. studied another panel, combing the markers AXIN2 and DKK1 (Additional file 6), 
in two independent TNM stage II populations $(n=65$ and $n=79$, respectively). In both populations, an association with poorer RFS was found (HR 3.84 95\% CI 1.14-12.43; $p<0.0004$, respectively) [45].

\section{Clinical translation}

For a definite conclusion on validity of a (prognostic) biomarker, a sufficient level of evidence (LoE) is needed. Methylation marker results (i.e., similar conclusions drawn in two or more independent study series) were ranked according to two established ranking schemes to obtain a comprehensive summary of the current evidence on prognostic epigenetic biomarkers in CRC $[36,37]$. For 12 single markers, and two multimarker panels, consistent results were reported in two or more publications or populations (Table 1). For four markers, the current LoE is level II, and for the other markers, LoE is lower. For 11 other markers and one multimarker panel, reported results are still too inconclusive to draw any conclusion on a possible prognostic biomarker effect (Table 1).

\section{Discussion}

In this review, we summarized published studies on prognostic DNA methylation markers for CRC. Although a large number of studies were identified and included in this review, the results from individual studies are difficult

Table 1 Level of evidence (LoE) of methylation markers assessed in two or more study series

\begin{tabular}{|c|c|c|c|c|}
\hline Marker & Population & Reported association & LoE & $\overline{\text { REMARK score Median (range) }}$ \\
\hline \multicolumn{5}{|l|}{ Consistent results $^{a}$} \\
\hline IGFBP3 & TNM stages 2-3 & Poor prognosis & $\|$ & $13.8(11-14)$ \\
\hline CDKN2A (p16) & TNM stages $1-3^{\mathrm{b}}$ & Poor prognosis & $\|$ & $11.5(6.5-17.5)$ \\
\hline WNT5a & TNM stages 1-4 & $\begin{array}{l}\text { No influence on } \\
\text { prognosis }\end{array}$ & $\|$ & $12.5(-)$ \\
\hline HPP1 & TNM stage 4 & Poor prognosis & $\|$ & $12.5(10-15)$ \\
\hline RET & TNM stage 2 & Poor prognosis & $\|-\| \|$ & $15.5(-)$ \\
\hline TFPA2E & TNM stages 1-4 & Good prognosis & III & $7.8(5-10.5)$ \\
\hline $\begin{array}{l}\text { Multimarker panel by } \\
\text { Gaedcke et al. [40] }\end{array}$ & $\begin{array}{l}\text { Locally advanced } \\
\text { rectal cancer }\end{array}$ & Poor prognosis & III & $12(-)$ \\
\hline $\begin{array}{l}\text { Multimarker panel by } \\
\text { Kandimalla et al. [45] }\end{array}$ & TNM stage II & Poor prognosis & III & 15 \\
\hline HLTF & TNM stages 1-4 & Poor prognosis & III-IV & $15(10-17.5)$ \\
\hline HPP1 & TNM stages 1-4 & Poor prognosis & IV & $12.5(10-15)$ \\
\hline EVL & TNM stages 1-4 & Poor prognosis & IV & 11 \\
\hline CD109 & TNM stages 1-4 & Poor prognosis & IV & 11 \\
\hline NRCAM & TNM stages 1-4 & Poor prognosis & IV & 11 \\
\hline FLNC & TNM stages 1-4 & Poor prognosis & IV & 11 \\
\hline \multicolumn{5}{|l|}{ Inconclusive results } \\
\hline BNIP3 & & & & $11.5(17.5-9)$ \\
\hline MLH1 & & & & $11.3(10-15)$ \\
\hline MGMT & & & & $12(5-17.5)$ \\
\hline RASSF1A & & & & $10.5(5-17.5)$ \\
\hline CDKN2A (p14) & & & & $8(5-17.5)$ \\
\hline APC & & & & $8.5(5-17.5)$ \\
\hline CHFR & & & & $16(17.5-14.5)$ \\
\hline ID4 & & & & $9.5(-)$ \\
\hline MYOD1 & & & & $9.5(9-10)$ \\
\hline SEPT9 & & & & $14.75(14.5-15)$ \\
\hline SFRP2 & & & & $11(10.5-11.5)$ \\
\hline MLH1 \& CDKN2A & & & & $11(10-12)$ \\
\hline
\end{tabular}

$a_{\geq 2}$ studies in similar populations showing consistent results

"'Summarized definition"; subgroup definitions differ between specific studies

${ }^{c}$ All studies included that contribute to LoE, or all overall results if LoE was inconclusive 
to compare due to the variation in study design, methodology, and survival endpoints. The number of prognostic biomarkers that were considered in multiple independent studies or patient populations is low, and promising results observed in one study are often not validated in another.

In 2005, with the publication of the REMARK guidelines, an attempt was made to improve the reporting quality of biomarker studies [25]. However, the observed variation in reporting sample series characteristics, statistical analyses, and sample sizes indicates that the REMARK guidelines are still not completely adapted and that accurate reporting of prognostic DNA methylation markers needs improvement (median REMARK score 10.7 out of 20 ). As we observed that studies which reported significant findings had lower REMARK scores (Fig. 3a, $p=0.005$ ) than studies which did not, a stricter adherence to the REMARK guidelines might be helpful, if we ever want to draw definitive conclusions on the role of a possible biomarker [27]. A more rigorous peer review by the scientific journals might be justified, in order to achieve this [123]. However, the REMARK guidelines are open to subjective interpretation, just as the scoring of the REMARK criteria. An inadequately reported methylation marker study does not imply that the methylation marker itself is not valuable, but it might hinder reproducibility.

The observed inconsistencies in individual study results might have various reasons, such as differences in sample collection, sample preparation, methods of DNA methylation analysis, and the genomic location of the assay $[22,124-126]$. The lack of standardization of different methods is a major issue in DNA methylation research. Differences in one or more technical aspects of the detection method used, including primer design, reagents, equipment, and protocols, can result in different DNA methylation measurements, even for the exact same genomic location, and can therefore have a substantial impact on the prognostic value of a test [127, 128]. Therefore, even consistently reported methylation marker results from this review should be treated carefully and validated in powered prospective studies. Comparing the results of methylation markers obtained with different methodology was not within the scope of this review, however should be addressed in a metaanalysis of the markers with most evidence.

The same lack of standardization holds true for the statistical analysis and the choice of study endpoints $[129,130]$. Whereas many studies focus on overall survival, other studies use cause-specific, disease-specific, or recurrence-free survival or do not specify the endpoints that were considered. As there are no uniform definitions of these endpoints, it is difficult to compare individual study results [34].

It is generally accepted that CRC is a heterogeneous disease with diverse subgroups, both on histological and molecular level [131-136]. Analyzing all CRC patients as one group will therefore obscure the true potential of some biomarkers. The majority of studies in this review (68 studies; 82\%) performed an analysis in TNM stages I-IV. As to date, TNM stage is one of the most important prognostic factors in cancer and the choice to include all TNM stages in one analysis will most likely influence the final conclusion. To overcome this, most studies also included one or more subgroup analyses, e.g., subgroups based on MSI, KRAS, or TNM stage. However, the definition of these subgroups is often very detailed or specific, thereby hampering the comparability of individual study results [38]. For example, 13 different subgroup analyses were identified for CDKN2A (p16) in this systematic review that could not be combined in a meta-analysis. In addition, different subgroups may have different baseline risks of death, thereby even further hindering comparison between different studies. Thus, on the one hand, analyzing CRC as a homogenous group could hinder the discovery of subgroup-specific biomarkers; however, on the other hand, analyzing subgroups that are too specific hinders the possibility of validation or meta-research.

Although the risk of introducing selection bias when selecting patients solely based on the availability of tissue is recognized [137], most studies in this review were retrospective (67 studies; $81 \%$ ) and conducted in a small number of patients (64 studies included $<200$ patients; $77 \%)$. Often, those study populations are often patient series that have been collected in research laboratories and University Hospitals based on the availability of samples. This, in addition to the availability of follow-up data, often determines the size of the study population. This approach however does not sufficiently contribute to answering the question whether a biomarker had prognostic value and if it should be implemented to improve patient care. It has already been shown that the prognostic effect of DNA methylation markers assessed in small sample series are often chance findings that cannot be reproduced in independent series $[138,139]$. Also in this review, we observed that statistically significant $p$ values tend to be reported more often in studies with a small population size (Fig. 3c). In order to increase the LoE of prognostic methylation markers, large-scale prospectively collected study populations are required. Therefore, we need a more structured approach, with collaborations between research groups, to obtain sufficient numbers of patient samples and validation populations to draw final conclusions on the prognostic relevance of a biomarker [140]. Twenty-three single markers and two multimarker panels have been investigated in two or more independent studies or patient populations. For eight biomarkers (IGFBP3, CDKN2A (p16), WNT5a, HPP1, RET, TFPA2E, HLTF, 
CD109, NRCAM, FLNC, and EVL) and the marker panels proposed by Gaedcke et al. (ADAP1, BARHL2, CABLES2, DOT1L, ERAS, ESRG, RNF220, ST6GALNAC5, TAF4, SLC2OA2) and Kandimalla et al. (AXIN2, $D K K 1)$, the results were consistent and a statistically significant association with prognosis was observed despite differences in study design and methodology. For five biomarkers (IGFBP3, CDKN2A (p16), WNT5a, $H P P 1$, and RET), the current LoE was II-III, indicating that a definitive conclusion on the prognostic influence of these markers is within reach. However, before a definitive conclusion on these markers can be made, a large, prospective study aimed at studying the clinical validity or a meta-analysis of studies with LoE II, which will be difficult given the differences in study design and methodology, is needed. Solely for WNT5a, additional studies assessing the prognostic influence might be omitted as results show no prognostic influence with a current LoE of II. For the other markers (TFPA2E, HLTF, $H P P 1$, and the multimarker panel proposed by Gaedcke et al.), current LoE is greater than or equal to III, indicating that even more validation is needed. To increase the LoE, these validation studies should preferably be prospectively designed, aimed at studying the biomarker effect, instead of retrospective case-series as these contribute little to increasing the LoE.

Reporting according to guidelines such as REMARK is important but not sufficient for successful translation of prognostic DNA methylation markers to clinical practice. Promising prognostic DNA methylation markers should be evaluated in multivariable prediction models to study their added prognostic value compared to the current reference standard (TNM stage) and other novel strategies to predict CRC prognosis [141-143]. Few of the included prognostic methylation marker studies in this review have assessed the incremental value of their prognostic DNA methylation marker in addition to the golden standard TNM staging system or other suggested prognostic markers such as grade of differentiation or microsatellite instability (MSI) [144]. In addition, other potential prognostic tools, such as histologic and molecular markers [145, 146], the immunoscore [147], circulating tumor DNA (ctDNA) [148], or the consensus molecular subtype (CMS) classification [149] should be taken into account in prediction models, as it is likely that a combination of several different types of markers will eventually yield the best predictive power.

\section{Conclusion}

Despite the widespread acceptance of epigenetic alterations as possible important biomarkers for CRC prognosis, very few biomarkers reach the point of usability in daily patient care and comprehensive overviews of the abundantly available biomarker results are lacking. In this review, we identified several promising markers that all require different amounts of further validation before definitive conclusions on their clinical applicability can be drawn. We also identified multiple problems hampering the comparison of individual study results including problems with population selection, study design, technical issues, and validation problems. Adhering to the REMARK guidelines might partly overcome these problems, and a more rigorous peer-review process specifically focusing on these reporting issues might be an essential step towards reducing the number of chance findings. In addition, biomarker research would benefit from a more structured approach in multidisciplinary collaborations, including clinicians, epidemiologists, statisticians, technicians, and molecular biologists, aiming to perform large, well-designed, and validated biomarker studies [140]. Only then will we be able to ultimately assess the clinical value of a biomarker.

\section{Additional files}

Additional file 1: Table S1. Search terms used for systematic review. (DOCX $83 \mathrm{~kb}$ )

Additional file 2: Table S2. REMARK checklist and description for scoring the reviewed studies. (DOCX $94 \mathrm{~kb}$ )

Additional file 3: Table S3. Characteristics of 83 included studies. (XLSX $95 \mathrm{~kb}$ )

Additional file 4: Table S4. Scoring of 83 included studies according to REMARK. (DOCX $114 \mathrm{~kb}$ )

Additional file 5: Table S5. Risk of potential bias and confounders of the included studies. Studies indicated by a " $X$ " potentially have an increased risk of bias, whereas studies indicated by a " $\sqrt{ }$ " potentially have a decreased risk of bias. (DOCX $108 \mathrm{~kb}$ )

Additional file 6: Table S6. Single markers and their characteristics that have been investigated in more than one study series, however, of which Cox regression survival analysis was not available for all markers. (DOCX 63 kb)

\section{Acknowledgements}

Not applicable.

Funding

Not applicable.

\section{Availability of data and materials}

All data generated or analyzed during this study are included in this published article and its supplementary information files.

\section{Authors' contributions}

$M D, D G, H G, M W, M v E, V M$, and KS contributed to the conception and design of the manuscript. MD and DG performed the systematic search, data extraction, and scoring of all articles. MD, AK, and KS analyzed and interpreted the data. MD and KS drafted the manuscript, and all authors critically revised the manuscript. All authors read and approved the final manuscript for publication.

Ethics approval and consent to participate Not applicable

Consent for publication

Not applicable 


\section{Competing interests}

The authors declare that they have no competing interests.

\section{Publisher's Note}

Springer Nature remains neutral with regard to jurisdictional claims in published maps and institutional affiliations.

\section{Author details}

'Department of Pathology, GROW - School for Oncology and Developmental Biology, Maastricht University Medical Center, Maastricht, The Netherlands. ${ }^{2}$ Pathology and Tumour Biology, Leeds Institute of Cancer and Pathology, University of Leeds, Leeds, UK. ${ }^{3}$ Department of Epidemiology, GROW School for Oncology and Developmental Biology, Maastricht University Medical Center, Maastricht, The Netherlands. ${ }^{4}$ Department of Clinical Genetics, University of Rotterdam, Rotterdam, The Netherlands.

\section{Received: 25 September 2017 Accepted: 21 February 2018} Published online: 14 March 2018

\section{References}

1. Ferlay J, Soerjomataram I, Dikshit R, Eser S, Mathers C, Rebelo M, Parkin DM, Forman D, Bray F. Cancer incidence and mortality worldwide: sources, methods and major patterns in GLOBOCAN 2012. Int J Cancer. 2015;136:E359-86

2. Haggar FA, Boushey RP. Colorectal cancer epidemiology: incidence, mortality, survival, and risk factors. Clin Colon Rectal Surg. 2009;22:191-7.

3. Engstrom PF, Arnoletti JP, Benson AB 3rd, Chen YJ, Choti MA, Coope HS, Covey A, Dilawari RA, Early DS, Enzinger PC, et al. NCCN clinical practice guidelines in oncology: colon cancer. J Natl Compr Cancer Netw. 2009:7:778-831.

4. Benson AB 3rd, Venook AP, Cederquist L, Chan E, Chen YJ, Cooper HS, Deming D, Engstrom PF, Enzinger PC, Fichera A, et al. Colon cancer, version 1.2017, NCCN clinical practice guidelines in oncology. J Natl Compr Cancer Netw. 2017:15:370-98.

5. Schmoll HJ, Van Cutsem E, Stein A, Valentini V, Glimelius B, Haustermans K, Nordlinger B, van de Velde CJ, Balmana J, Regula J, et al. ESMO consensus guidelines for management of patients with colon and rectal cancer. A personalized approach to clinical decision making. Ann Oncol. 2012;23:2479-516.

6. Van Cutsem E, Cervantes A, Nordlinger B, Arnold D, Group EGW. Metastatic colorectal cancer: ESMO clinical practice guidelines for diagnosis, treatment and follow-up. Ann Oncol. 2014;25(Suppl 3):iii1-9.

7. Laird PW. The power and the promise of DNA methylation markers. Nat Rev Cancer. 2003;3:253-66.

8. Okugawa Y, Grady WM, Goel A. Epigenetic alterations in colorectal cancer: emerging biomarkers. Gastroenterology. 2015;149:1204-25. e1212

9. Vaiopoulos AG, Athanasoula K, Papavassiliou AG. Epigenetic modifications in colorectal cancer: molecular insights and therapeutic challenges. Biochim Biophys Acta. 1842;2014:971-80.

10. El Bairi K, Tariq K, Himri I, Jaafari A, Smaili W, Kandhro AH, Gouri A, Ghazi B: Decoding colorectal cancer epigenomics. Cancer Genet 2018, 220:49-76.

11. Poste G. Bring on the biomarkers. Nature. 2011;469:156-7.

12. Church TR, Wandell M, Lofton-Day C, Mongin SJ, Burger M, Payne SR, Castanos-Velez E, Blumenstein BA, Rosch T, Osborn N, et al. Prospective evaluation of methylated SEPT9 in plasma for detection of asymptomatic colorectal cancer. Gut. 2014;63:317-25.

13. Smits KM, Cleven AH, Weijenberg MP, Hughes LA, Herman JG, de Bruine AP, van Engeland M: Pharmacoepigenomics in colorectal cancer: a step forward in predicting prognosis and treatment response. Pharmacogenomics 2008, 9:1903-1916.

14. Kim MS, Lee J, Sidransky D. DNA methylation markers in colorectal cancer. Cancer Metastasis Rev. 2010;29:181-206.

15. Coppede F. Epigenetic biomarkers of colorectal cancer: focus on DNA methylation. Cancer Lett. 2014;342:238-47

16. Lam K, Pan K, Linnekamp JF, Medema JP, Kandimalla R. DNA methylation based biomarkers in colorectal cancer: a systematic review. Biochim Biophys Acta. 1866:2016:106-20.

17. deVos T, Molnar B. Screening for colorectal cancer based on the promoter methylation status of the septin 9 gene in plasma cell free DNA. J Clin Epigenetics. 2017;3:1-6
18. Imperiale TF, Ransohoff DF, Itzkowitz SH, Levin TR, Lavin P, Lidgard GP, Ahlquist DA, Berger BM. Multitarget stool DNA testing for colorectal-cancer screening. N Engl J Med. 2014;370:1287-97.

19. Ransohoff DF. Challenges and opportunities in evaluating diagnostic tests. $J$ Clin Epidemiol. 2002;55:1178-82.

20. Ioannidis JP. Biomarker failures. Clin Chem. 2013:59:202-4.

21. Ioannidis JPA, Bossuyt PMM. Waste, leaks, and failures in the biomarker pipeline. Clin Chem. 2017:63:963-72.

22. Poste G, Compton CC, Barker AD. The national biomarker development alliance: confronting the poor productivity of biomarker research and development. Expert Rev Mol Diagn. 2015;15:211-8.

23. Pharo HD, Honne H, Vedeld HM, Dahl C, Andresen K, Liestol K, Jeanmougin M, Guldberg P, Lind GE. Experimental factors affecting the robustness of DNA methylation analysis. Sci Rep. 2016;6:33936.

24. Lind GE, van Engeland M. Details matter: the role of genomic location and assay standardization in DNA methylation analyses. Epigenomics. 2017:9:933-5

25. McShane LM, Altman DG, Sauerbrei W, Taube SE, Gion M, Clark GM, Statistics subcommittee of the NCIEWGoCD. REporting recommendations for tumour MARKer prognostic studies (REMARK). Br J Cancer. 2005;93:387-91.

26. Mallett S, Timmer A, Sauerbrei W, Altman DG. Reporting of prognostic studies of tumour markers: a review of published articles in relation to REMARK guidelines. Br J Cancer. 2010;102:173-80.

27. Sekula P, Mallett S, Altman DG, Sauerbrei W. Did the reporting of prognostic studies of tumour markers improve since the introduction of REMARK guideline? A comparison of reporting in published articles. PLoS One. 2017; 12:e0178531.

28. Hughes LA, Khalid-de Bakker CA, Smits KM, van den Brandt PA, Jonkers D, Ahuja N, Herman JG, Weijenberg MP, van Engeland M: The CpG island methylator phenotype in colorectal cancer: progress and problems. Biochim Biophys Acta 2012, 1825:77-85

29. Voorham QJ, Rondagh EJ, Knol DL, van Engeland M, Carvalho B, Meijer GA, Sanduleanu S. Tracking the molecular features of nonpolypoid colorectal neoplasms: a systematic review and meta-analysis. Am J Gastroenterol. 2013;108:1042-56.

30. Juo YY, Johnston FM, Zhang DY, Juo HH, Wang H, Pappou EP, Yu T, Easwaran H, Baylin S, van Engeland M, Ahuja N. Prognostic value of CpG island methylator phenotype among colorectal cancer patients: a systematic review and meta-analysis. Ann Oncol. 2014;25:2314-27.

31. Jia M, Gao X, Zhang Y, Hoffmeister M, Brenner H. Different definitions of CpG island methylator phenotype and outcomes of colorectal cancer: a systematic review. Clin Epigenetics. 2016;8:25.

32. Zong $L$, Abe M, Ji J, Zhu WG, Yu D. Tracking the correlation between CpG island methylator phenotype and other molecular features and clinicopathological features in human colorectal cancers: a systematic review and meta-analysis. Clin Transl Gastroenterol. 2016;7:e151.

33. Moher D, Liberati A, Tetzlaff J, Altman DG, Group P. Preferred reporting items for systematic reviews and meta-analyses: the PRISMA statement. Int J Surg. 2010:8:336-41.

34. Altman DG, McShane LM, Sauerbrei W, Taube SE. Reporting recommendations for tumor marker prognostic studies (REMARK): explanation and elaboration. PLoS Med. 2012;9:e1001216.

35. Guyatt GH, Oxman AD, Vist GE, Kunz R, Falck-Ytter Y, Alonso-Coello P, Schunemann HJ, Group GW. GRADE: an emerging consensus on rating quality of evidence and strength of recommendations. BMJ. 2008;336:924-6.

36. OCEBM Levels of Evidence Working Group. "The Oxford Levels of Evidence 2". Oxford Centre for Evidence-Based Medicine. https://www.cebm.net/ index.aspx?o=5653.

37. Hayes DF. Biomarker validation and testing. Mol Oncol. 2015;9:960-6.

38. Kyzas PA, Denaxa-Kyza D, loannidis JP. Almost all articles on cancer prognostic markers report statistically significant results. Eur J Cancer. 2007:43:2559-79.

39. McGauran N, Wieseler B, Kreis J, Schuler YB, Kolsch H, Kaiser T. Reporting bias in medical research--a narrative review. Trials. 2010;11:37.

40. Gaedcke J, Leha A, Claus R, Weichenhan D, Jung K, Kitz J, Grade M, Wolff HA, Jo P, Doyen J, et al. Identification of a DNA methylation signature to predict disease-free survival in locally advanced rectal cancer. Oncotarget. 2014:5:8123-35.

41. Luo X, Huang R, Sun H, Liu Y, Bi H, Li J, Yu H, Sun J, Lin S, Cui B, Zhao Y. Methylation of a panel of genes in peripheral blood leukocytes is associated with colorectal cancer. Sci Rep. 2016;6:29922. 
42. Benard A, Zeestraten EC, Goossens-Beumer IJ, Putter H, van de Velde CJ, Hoon DS, Kuppen PJ. DNA methylation of apoptosis genes in rectal cancer predicts patient survival and tumor recurrence. Apoptosis. 2014;19:1581-93.

43. Chen SP, Chiu SC, Wu CC, Lin SZ, Kang JC, Chen YL, Lin PC, Pang CY, Harn HJ. The association of methylation in the promoter of APC and MGMT and the prognosis of Taiwanese CRC patients. Genet Test Mol Biomarkers. 2009;13:67-71.

44. de Sousa EMF, Colak S, Buikhuisen J, Koster J, Cameron K, de Jong JH, Tuynman JB, Prasetyanti PR, Fessler E, van den Bergh SP, et al. Methylation of cancer-stem-cell-associated Wnt target genes predicts poor prognosis in colorectal cancer patients. Cell Stem Cell. 2011;9:476-85.

45. Kandimalla R, Linnekamp JF, van Hooff S, Castells A, Llor X, Andreu M, Jover R, Goel A, Medema JP: Methylation of WNT target genes AXIN2 and DKK1 as robust biomarkers for recurrence prediction in stage $\|$ colon cancer. Oncogene 2017, 6:e308.

46. Sangplod P, Kanngurn S, Boonpipattanapong T, Ruangrat $P$, Sangkhathat $S$. Expression of BMP6 is associated with its methylation status in colorectal cancer tissue but lacks prognostic significance. Asian Pac J Cancer Prev. 2014;15:7091-5.

47. Shimizu S, lida S, Ishiguro M, Uetake H, Ishikawa T, Takagi Y, Kobayashi H, Higuchi T, Enomoto M, Mogushi K, et al. Methylated BNIP3 gene in colorectal cancer prognosis. Oncol Lett. 2010;1:865-72.

48. Yi JM, Dhir M, Van Neste L, Downing SR, Jeschke J, Glockner SC, de Freitas Calmon M, Hooker CM, Funes JM, Boshoff C, et al. Genomic and epigenomic integration identifies a prognostic signature in colon cancer. Clin Cancer Res. 2011;17:1535-45.

49. Wang Z, Yuan $X$, Jiao N, Zhu H, Zhang Y, Tong J. CDH13 and FLBN3 gene methylation are associated with poor prognosis in colorectal cancer. Pathol Oncol Res. 2012;18:263-70.

50. Liang JT, Chang KJ, Chen JC, Lee CC, Cheng YM, Hsu HC, Wu MS, Wang SM, Lin JT, Cheng AL. Hypermethylation of the p16 gene in sporadic T3NOMO stage colorectal cancers: association with DNA replication error and shorter survival. Oncology. 1999;57:149-56.

51. Esteller M, Gonzalez S, Risques RA, Marcuello E, Mangues R, Germa JR, Herman JG, Capella G, Peinado MA. K-ras and p16 aberrations confer poor prognosis in human colorectal cancer. J Clin Oncol. 2001;19:299-304.

52. Maeda K, Kawakami K, Ishida Y, Ishiguro K, Omura K, Watanabe G. Hypermethylation of the CDKN2A gene in colorectal cancer is associated with shorter survival. Oncol Rep. 2003;10:935-8.

53. Sanz-Casla MT, Maestro ML, Vidaurreta M, Maestro C, Arroyo M, Cerdan J. p16 Gene methylation in colorectal tumors: correlation with clinicopathological features and prognostic value. Dig Dis. 2005;23:151-5.

54. Nakayama G, Hibi K, Kodera Y, Koike M, Fujiwara M, Nakao A. P16 methylation in serum as a potential marker for the malignancy of colorectal carcinoma. Anticancer Res. 2007:27:3367-70.

55. Wettergren Y, Odin E, Nilsson S, Carlsson G, Gustavsson B. p16INK4a gene promoter hypermethylation in mucosa as a prognostic factor for patients with colorectal cancer. Mol Med. 2008;14:412-21.

56. Wettergren $Y$, Odin E, Carlsson G, Gustavsson B. MTHFR, MTR, and MTRR polymorphisms in relation to p16INK4A hypermethylation in mucosa of patients with colorectal cancer. Mol Med. 2010;16:425-32.

57. Malhotra P, Kochhar R, Vaiphei K, Wig JD, Mahmood S. Aberrant promoter methylation of p16 in colorectal adenocarcinoma in North Indian patients. World J Gastrointest Oncol. 2010;2:295-303.

58. Mitomi H, Fukui N, Tanaka N, Kanazawa H, Saito T, Matsuoka T, Yao T. Aberrant p16((INK4a)) methylation is a frequent event in colorectal cancers: prognostic value and relation to mRNA expression and immunoreactivity. J Cancer Res Clin Oncol. 2010;136:323-31.

59. Shima K, Nosho K, Baba Y, Cantor M, Meyerhardt JA, Giovannucci EL, Fuchs CS, Ogino S. Prognostic significance of CDKN2A (p16) promoter methylation and loss of expression in 902 colorectal cancers: cohort study and literature review. Int J Cancer. 2011;128:1080-94.

60. Bihl MP, Foerster A, Lugli A, Zlobec I. Characterization of CDKN2A(p16) methylation and impact in colorectal cancer: systematic analysis using pyrosequencing. J Transl Med. 2012;10:173.

61. Veganzones-de-Castro S, Rafael-Fernandez S, Vidaurreta-Lazaro M, de-laOrden V, Mediero-Valeros B, Fernandez C, Maestro-de las Casas ML: p16 gene methylation in colorectal cancer patients with long-term follow-up. Rev Esp Enferm Dig 2012, 104:111-117.

62. Kohonen-Corish MR, Tseung J, Chan C, Currey N, Dent OF, Clarke S, Bokey L, Chapuis PH. KRAS mutations and CDKN2A promoter methylation show an interactive adverse effect on survival and predict recurrence of rectal cancer Int J Cancer. 2014;134:2820-8.

63. Ishiguro A, Takahata T, Saito M, Yoshiya G, Tamura Y, Sasaki M, Munakata A. Influence of methylated p15 and p16 genes on clinicopathological features in colorectal cancer. J Gastroenterol Hepatol. 2006;21:1334-9.

64. Miladi-Abdennadher I, Abdelmaksoud-Damak R, Ayadi L, Khabir A, Frikha F, Kallel L, Frikha M, Sellami-Boudawara T, Gargouri A, Mokdad-Gargouri R. Aberrant methylation of hMLH1 and p16INK4a in Tunisian patients with sporadic colorectal adenocarcinoma. Biosci Rep. 2011;31:257-64.

65. lida S, Kato S, Ishiguro M, Matsuyama T, Ishikawa T, Kobayashi H, Higuchi T, Uetake $\mathrm{H}$, Enomoto M, Sugihara K. PIK3CA mutation and methylation influences the outcome of colorectal cancer. Oncol Lett. 2012;3:565-70.

66. Veganzones S, Maestro ML, Rafael S, de la Orden V, Vidaurreta M, Mediero B, Espantaleon M, Cerdan J, Diaz-Rubio E. Combined methylation of p16 and hMLH1 (CMETH2) discriminates a subpopulation with better prognosis in colorectal cancer patients with microsatellite instability tumors. Tumour Biol. 2015;36:3853-61.

67. Krtolica K, Krajnovic M, Usaj-Knezevic S, Babic D, Jovanovic D, Dimitrijevic B. Comethylation of p16 and MGMT genes in colorectal carcinoma: correlation with clinicopathological features and prognostic value. World J Gastroenterol. 2007;13:1187-94.

68. Kamiyama H, Noda H, Takata O, Suzuki K, Kawamura Y, Konishi F. Promoter hypermethylation of tumor-related genes in peritoneal lavage and the prognosis of patients with colorectal cancer. J Surg Oncol. 2009;100:69-74.

69. Kuan JC, Wu CC, Sun CA, Chu CM, Lin FG, Hsu CH, Kan PC, Lin SC, Yang T, Chou YC. DNA methylation combinations in adjacent normal colon tissue predict cancer recurrence: evidence from a clinical cohort study. PLoS One. 2015;10:e0123396.

70. Yang W, Wang X, Li X, Wang M, Chen X, Wu X, Wang Y, Fan Y, Jin H. The specific methylation characteristics of cancer related genes in Chinese colorectal cancer patients. Tumour Biol. 2014;35:8267-79.

71. Jiang G, Luo C, Sun M, Zhao Z, Li W, Chen K, Fan T. Methylation of CDX2 as a predictor in poor clinical outcome of patients with colorectal cancer. Genet Test Mol Biomarkers. 2016;20:710-4.

72. Tanaka M, Chang P, Li Y, Li D, Overman M, Maru DM, Sethi S, Phillips J, Bland GL, Abbruzzese JL, Eng C. Association of CHFR promoter methylation with disease recurrence in locally advanced colon cancer. Clin Cancer Res. 2011;17:4531-40.

73. Cleven AH, Derks S, Draht MX, Smits KM, Melotte $V$, Van Neste L, Tournier B, Jooste V, Chapusot C, Weijenberg MP, et al. CHFR promoter methylation indicates poor prognosis in stage II microsatellite stable colorectal cancer. Clin Cancer Res. 2014;20:3261-71.

74. Wang S, Dong Y, Zhang Y, Wang X, Xu L, Yang S, Li X, Dong H, Xu L, Su L, et al. DACT2 is a functional tumor suppressor through inhibiting Wnt/betacatenin pathway and associated with poor survival in colon cancer. Oncogene. 2015;34:2575-85.

75. Cui T, Chen Y, Yang L, Knosel T, Zoller K, Huber O, Petersen I. DSC3 expression is regulated by p53, and methylation of DSC3 DNA is a prognostic marker in human colorectal cancer. Br J Cancer. 2011;104:1013-9.

76. Rawluszko-Wieczorek AA, Horbacka K, Krokowicz P, Misztal M, Jagodzinski PP. Prognostic potential of DNA methylation and transcript levels of HIF1A and EPAS1 in colorectal cancer. Mol Cancer Res. 2014;12:1112-27.

77. $\mathrm{Xu} \mathrm{Z}$, Chen H, Liu D, Huo J. Fibulin-1 is downregulated through promoter hypermethylation in colorectal cancer: a CONSORT study. Medicine (Baltimore). 2015;94:e663.

78. Wallner M, Herbst A, Behrens A, Crispin A, Stieber P, Goke B, Lamerz R, Kolligs FT. Methylation of serum DNA is an independent prognostic marker in colorectal cancer. Clin Cancer Res. 2006;12:7347-52.

79. Herbst A, Wallner M, Rahmig K, Stieber P, Crispin A, Lamerz R, Kolligs FT. Methylation of helicase-like transcription factor in serum of patients with colorectal cancer is an independent predictor of disease recurrence. Eur J Gastroenterol Hepatol. 2009;21:565-9.

80. Philipp AB, Stieber P, Nagel D, Neumann J, Spelsberg F, Jung A, Lamerz R, Herbst A, Kolligs FT. Prognostic role of methylated free circulating DNA in colorectal cancer. Int J Cancer. 2012;131:2308-19.

81. Philipp AB, Nagel D, Stieber P, Lamerz R, Thalhammer I, Herbst A, Kolligs FT. Circulating cell-free methylated DNA and lactate dehydrogenase release in colorectal cancer. BMC Cancer. 2014;14:245.

82. Herbst A, Vdovin N, Gacesa S, Philipp A, Nagel D, Holdt LM, Op den Winkel M, Heinemann V, Stieber P, Graeven U, et al. Methylated free-circulating HPP1 DNA is an early response marker in patients with metastatic colorectal cancer. Int J Cancer. 2017;140:2134-44. 
83. Jensen $L H$, Rasmussen AA, Byriel L, Kuramochi $H$, Cruger DG, Lindebjerg J, Danenberg PV, Jakobsen A, Danenberg K. Regulation of MLH1 mRNA and protein expression by promoter methylation in primary colorectal cancer: a descriptive and prognostic cancer marker study. Cell Oncol (Dordr). 2013;36:411-9.

84. Wang Y, Li D, Li X, Teng C, Zhu L, Cui B, Zhao Y, Hu F. Prognostic significance of hMLH1/hMSH2 gene mutations and hMLH1 promoter methylation in sporadic colorectal cancer. Med Oncol. 2014;31:39.

85. Aoyagi H, lida S, Uetake H, Ishikawa T, Takagi Y, Kobayashi H, Higuchi T, Yasuno M, Enomoto M, Sugihara K. Effect of classification based on combination of mutation and methylation in colorectal cancer prognosis. Oncol Rep. 2011;25:789-94.

86. Malhotra P, Anwar M, Kochhar R, Ahmad S, Vaiphei K, Mahmood S. Promoter methylation and immunohistochemical expression of hMLH1 and hMSH2 in sporadic colorectal cancer: a study from India. Tumour Biol. 2014;35:3679-87.

87. Katoh H, Yamashita K, Waraya M, Margalit O, Ooki A, Tamaki H, Sakagami H, Kokubo K, Sidransky D, Watanabe M. Epigenetic silencing of HOPX promotes cancer progression in colorectal cancer. Neoplasia. 2012;14:559-71.

88. Umetani N, Takeuchi H, Fujimoto A, Shinozaki M, Bilchik AJ, Hoon DS. Epigenetic inactivation of ID4 in colorectal carcinomas correlates with poor differentiation and unfavorable prognosis. Clin Cancer Res. 2004;10:7475-83.

89. Fu T, Pappou EP, Guzzetta AA, Calmon MF, Sun L, Herrera A, Li F, Wolfgang $\mathrm{CL}$, Baylin SB, lacobuzio-Donahue CA, et al. IGFBP-3 gene methylation in primary tumor predicts recurrence of stage II colorectal cancers. Ann Surg. 2016;263(2):337-344

90. Perez-Carbonell L, Balaguer F, Toiyama Y, Egoavil C, Rojas E, Guarinos C, Andreu M, Llor X, Castells A, Jover R, et al. IGFBP3 methylation is a novel diagnostic and predictive biomarker in colorectal cancer. PLoS One. 2014;9:e104285.

91. Baba Y, Nosho K, Shima K, Huttenhower C, Tanaka N, Hazra A, Giovannucci EL, Fuchs CS, Ogino S. Hypomethylation of the IGF2 DMR in colorectal tumors, detected by bisulfite pyrosequencing, is associated with poor prognosis. Gastroenterology. 2010;139:1855-64.

92. Moya P, Esteban S, Fernandez-Suarez A, Maestro M, Morente M, SanchezCarbayo M. KiSS-1 methylation and protein expression patterns contribute to diagnostic and prognostic assessments in tissue specimens for colorectal cancer. Tumour Biol. 2013;34:471-9.

93. Su S, Hong F, Liang Y, Zhou J, Liang Y, Chen K, Wang X, Wang Z, Wang Z, Chang $C$, et al. Lgr5 methylation in cancer stem cell differentiation and prognosis-prediction in colorectal cancer. PLoS One. 2015;10:e0143513.

94. Shima K, Morikawa T, Baba Y, Nosho K, Suzuki M, Yamauchi M, Hayashi M, Giovannucci E, Fuchs CS, Ogino S. MGMT promoter methylation, loss of expression and prognosis in 855 colorectal cancers. Cancer Causes Control. 2011:22:301-9.

95. Oliver JA, Ortiz R, Melguizo C, Alvarez PJ, Gomez-Millan J, Prados J. Prognostic impact of MGMT promoter methylation and MGMT and CD133 expression in colorectal adenocarcinoma. BMC Cancer. 2014;14:511.

96. Shannon B, Kay P, House A, lacopetta B. Hypermethylation of the MYF-3 gene in colorectal cancers: associations with pathological features and with microsatellite instability. Int J Cancer. 1999:84:109-13.

97. Hiranuma C, Kawakami K, Oyama K, Ota N, Omura K, Watanabe G. Hypermethylation of the MYOD1 gene is a novel prognostic factor in patients with colorectal cancer. Int J Mol Med. 2004;13:413-7.

98. Esteban S, Moya P, Fernandez-Suarez A, Vidaurreta M, Gonzalez-Peramato P, Sanchez-Carbayo M. Diagnostic and prognostic utility of methylation and protein expression patterns of myopodin in colon cancer. Tumour Biol. 2012;33:337-46

99. Chaar I, Amara S, Elamine OE, Khiari M, Ounissi D, Khalfallah T, Ben Hmida A Mzabi S, Bouraoui S. Biological significance of promoter hypermethylation of p14/ARF gene: relationships to p53 mutational status in Tunisian population with colorectal carcinoma. Tumour Biol. 2014;35:1439-49.

100. Heitzer E, Artl M, Filipits M, Resel M, Graf R, Weissenbacher B, Lax S, Gnant M, Wrba F, Greil R, et al. Differential survival trends of stage II colorectal cancer patients relate to promoter methylation status of PCDH10, SPARC, and UCHL1. Mod Pathol. 2014;27:906-15.

101. Pancione M, Sabatino L, Fucci A, Carafa V, Nebbioso A, Forte N, Febbraro A, Parente D, Ambrosino C, Normanno N, et al. Epigenetic silencing of peroxisome proliferator-activated receptor gamma is a biomarker for colorectal cancer progression and adverse patients' outcome. PLoS One. 2010;5:e14229.

102. Lin PC, Lin JK, Lin HH, Lan YT, Lin CC, Yang SH, Chen WS, Liang WY, Jiang JK, Chang SC. A comprehensive analysis of phosphatase and tensin homolog deleted on chromosome 10 (PTEN) loss in colorectal cancer. World J Surg Oncol. 2015;13:186.

103. Miladi-Abdennadher I, Abdelmaksoud-Damak R, Ayadi L, Khabir A, Frikha F, Kallel L, Amouri A, Frikha M, Sellami-Boudawara T, Gargouri A, MokdadGargouri R. Hypermethylation of RARbeta2 correlates with high COX-2 expression and poor prognosis in patients with colorectal carcinoma. Tumour Biol. 2010;31:503-11.

104. Chen SP, Wu CC, Huang SY, Kang JC, Chiu SC, Yang KL, Pang CY. Beta-catenin and K-ras mutations and RASSF1A promoter methylation in Taiwanese colorectal cancer patients. Genet Test Mol Biomarkers. 2012;16:1277-81.

105. Nilsson TK, Lof-Ohlin ZM, Sun XF. DNA methylation of the p14ARF, RASSF1A and APC1A genes as an independent prognostic factor in colorectal cancer patients. Int J Oncol. 2013:42:127-33.

106. Matthaios D, Balgkouranidou I, Karayiannakis A, Bolanaki H, Xenidis N, Amarantidis K, Chelis L, Romanidis K, Chatzaki A, Lianidou E, et al. Methylation status of the APC and RASSF1A promoter in cell-free circulating DNA and its prognostic role in patients with colorectal cancer. Oncol Lett. 2016:12:748-56.

107. Draht MX, Smits KM, Tournier B, Jooste V, Chapusot C, Carvalho B, Cleven $\mathrm{AH}$, Derks S, Wouters KA, Belt EJ, et al. Promoter CpG island methylation of RET predicts poor prognosis in stage II colorectal cancer patients. Mol Oncol. 2014:8:679-88.

108. Tham C, Chew M, Soong R, Lim J, Ang M, Tang C, Zhao Y, Ong SY, Liu Y. Postoperative serum methylation levels of TAC1 and SEPT9 are independent predictors of recurrence and survival of patients with colorectal cancer. Cancer. 2014;120:3131-41.

109. Liu Y, Chew MH, Tham CK, Tang CL, Ong SY, Zhao Y. Methylation of serum SST gene is an independent prognostic marker in colorectal cancer. Am J Cancer Res. 2016;6:2098-108.

110. Dallol A, Al-Maghrabi J, Buhmeida A, Gari MA, Chaudhary AG, Schulten HJ, Abuzenadah AM, Al-Ahwal MS, Sibiany A, Al-Qahtani MH. Methylation of the polycomb group target genes is a possible biomarker for favorable prognosis in colorectal cancer. Cancer Epidemiol Biomark Prev. 2012;21:2069-75.

111. Tang D, Liu J, Wang DR, Yu HF, Li YK, Zhang JQ. Diagnostic and prognostic value of the methylation status of secreted frizzled-related protein 2 in colorectal cancer. Clin Invest Med. 2011:34:E88-95.

112. Tsai MH, Chen WC, Yu SL, Chen CC, Jao TM, Huang CY, Tzeng ST, Yen SJ, Yang YC. DNA hypermethylation of SHISA3 in colorectal cancer: an independent predictor of poor prognosis. Ann Surg Oncol. 2015;3:1481-9.

113. He T, Zhang M, Zheng R, Zheng S, Linghu E, Herman JG, Guo M. Methylation of SLFN11 is a marker of poor prognosis and cisplatin resistance in colorectal cancer. Epigenomics. 2017;9:849-62.

114. Kang XC, Chen ML, Yang F, Gao BQ, Yang QH, Zheng WW, Hao S. Promoter methylation and expression of SOCS-1 affect clinical outcome and epithelial-mesenchymal transition in colorectal cancer. Biomed Pharmacother. 2016;80:23-9.

115. Yang Z, Huo L, Chen H, Ni B, Xiang J, Kang L, Wang L, Peng J, Yuan Y Wang J. Hypermethylation and prognostic implication of Syk gene in human colorectal cancer. Med Oncol. 2013;30:586.

116. Yu J, Ma X, Cheung KF, Li X, Tian L, Wang S, Wu CW, Wu WK, He M, Wang $M$, et al. Epigenetic inactivation of T-box transcription factor 5, a novel tumor suppressor gene, is associated with colon cancer. Oncogene. 2010;29:6464-74.

117. Zhang ZM, Wang Y, Huang R, Liu YP, Li X, Hu FL, Zhu L, Wang F, Cui BB, Dong XS, Zhao YS. TFAP2E hypermethylation was associated with survival advantage in patients with colorectal cancer. J Cancer Res Clin Oncol. 2014;140:2119-27.

118. Park SJ, Kim SM, Hong YS, Lee JL, Kim JE, Kim KP, Hong SM, Jin DH, Kim CW Yoon YS, et al. TFAP2E methylation status and prognosis of patients with radically resected colorectal cancer. Oncology. 2015;88:122-32.

119. Beggs AD, Dilworth MP, Domingo E, Midgley R, Kerr D, Tomlinson IP, Middleton GW. Methylation changes in the TFAP2E promoter region are associated with BRAF mutation and poorer overall \& disease free survival in colorectal cancer. Oncoscience. 2015;2:508-16.

120. Ruppenthal RD, Nicolini C, Filho AF, Meurer R, Damin AP, Rohe A, Alexandre CO, Damin DC. TWIST1 promoter methylation in primary colorectal carcinoma. Pathol Oncol Res. 2011;17:867-72.

121. Abdelmaksoud-Dammak R, Miladi-Abdennadher I, Saadallah-Kallel A, Khabir A, Sellami-Boudawara T, Frikha M, Daoud J, Mokdad-Gargouri R. 
Downregulation of WIF-1 and Wnt5a in patients with colorectal carcinoma: clinical significance. Tumour Biol. 2014;35:7975-82.

122. Rawson JB, Mrkonjic M, Daftary D, Dicks E, Buchanan DD, Younghusband HB, Parfrey PS, Young JP, Pollett A, Green RC, et al. Promoter methylation of Wnt5a is associated with microsatellite instability and BRAF V600E mutation in two large populations of colorectal cancer patients. Br J Cancer. 2011;104:1906-12.

123. Stevens A, Shamseer L, Weinstein E, Yazdi F, Turner L, Thielman J, Altman DG, Hirst A, Hoey J, Palepu A, et al. Relation of completeness of reporting of health research to journals' endorsement of reporting guidelines: systematic review. BMJ. 2014;348:g3804

124. Ioannidis JP, Greenland S, Hlatky MA, Khoury MJ, Macleod MR, Moher D, Schulz KF, Tibshirani R. Increasing value and reducing waste in research design, conduct, and analysis. Lancet. 2014;383:166-75.

125. Bustin SA, Benes V, Garson JA, Hellemans J, Huggett J, Kubista M, Mueller R, Nolan T, Pfaffl MW, Shipley GL, et al. The MIQE guidelines: minimum information for publication of quantitative real-time PCR experiments. Clin Chem. 2009;55:611-22

126. Pepe MS, Li Cl, Feng Z. Improving the quality of biomarker discovery research: the right samples and enough of them. Cancer Epidemiol Biomark Prev. 2015;24:944-50.

127. van Vlodrop IJ, Niessen HE, Derks S, Baldewijns MM, van Criekinge W, Herman JG, van Engeland M. Analysis of promoter CpG island hypermethylation in cancer: location, location, location. Clin Cancer Res. 2011:17:4225-31.

128. Draht MX, Smits KM, Jooste V, Tournier B, Vervoort M, Ramaekers C, Chapusot C, Weijenberg MP, van Engeland M, Melotte V. Analysis of RET promoter CpG island methylation using methylation-specific PCR (MSP), pyrosequencing, and methylation-sensitive high-resolution melting (MS-HRM): impact on stage II colon cancer patient outcome. Clin Epigenetics. 2016;8:44.

129. Burton A, Altman DG. Missing covariate data within cancer prognostic studies: a review of current reporting and proposed guidelines. Br J Cancer. 2004;91:4-8.

130. Ensor JE. Biomarker validation: common data analysis concerns. Oncologist. 2014;19:886-91.

131. Vogelstein B, Fearon ER, Hamilton SR, Kern SE, Preisinger AC, Leppert M, Nakamura Y, White R, Smits AM, Bos JL. Genetic alterations during colorectal-tumor development. N Engl J Med. 1988;319:525-32.

132. Hermsen M, Postma C, Baak J, Weiss M, Rapallo A, Sciutto A, Roemen G, Arends JW, Williams R, Giaretti W, et al. Colorectal adenoma to carcinoma progression follows multiple pathways of chromosomal instability. Gastroenterology. 2002;123:1109-19.

133. Boland CR, Goel A. Microsatellite instability in colorectal cancer. Gastroenterology. 2010;138:2073-87. e2073

134. Suzuki H, Yamamoto E, Maruyama R, Niinuma T, Kai M. Biological significance of the CpG island methylator phenotype. Biochem Biophys Res Commun. 2014:455:35-42.

135. Toyota M, Ahuja N, Ohe-Toyota M, Herman JG, Baylin SB, Issa JP. CpG island methylator phenotype in colorectal cancer. Proc Natl Acad Sci U S A. 1999:96:8681-6.

136. Sadanandam A, Lyssiotis CA, Homicsko K, Collisson EA, Gibb WJ, Wullschleger S, Ostos LC, Lannon WA, Grotzinger C, Del Rio M, et al. A colorectal cancer classification system that associates cellular phenotype and responses to therapy. Nat Med. 2013;19:619-25.

137. Barker AD, Compton CC, Poste G. The National Biomarker Development Alliance accelerating the translation of biomarkers to the clinic. Biomark Med. 2014;8:873-6.

138. Pintilie M, lakovlev V, Fyles A, Hedley D, Milosevic M, Hill RP. Heterogeneity and power in clinical biomarker studies. J Clin Oncol. 2009;27:1517-21.

139. Ioannidis JP, Panagiotou OA. Comparison of effect sizes associated with biomarkers reported in highly cited individual articles and in subsequent meta-analyses. JAMA. 2011;305:2200-10.

140. van Gool AJ, Bietrix F, Caldenhoven E, Zatloukal K, Scherer A, Litton JE, Meijer G, Blomberg N, Smith A, Mons B, et al. Bridging the translational innovation gap through good biomarker practice. Nat Rev Drug Discov. 2017;16(9):587-58.

141. Moons KG, Kengne AP, Woodward M, Royston P, Vergouwe Y, Altman DG, Grobbee DE. Risk prediction models: I. Development, internal validation, and assessing the incremental value of a new (bio)marker. Heart. 2012;98:683-90.

142. Moons KG, Kengne AP, Grobbee DE, Royston P, Vergouwe Y, Altman DG, Woodward M. Risk prediction models: II. External validation, model updating, and impact assessment. Heart. 2012;98:691-8.
143. Moons KG, Royston P, Vergouwe Y, Grobbee DE, Altman DG. Prognosis and prognostic research: what, why, and how? BMJ. 2009:338:b375.

144. Sinicrope FA, Sargent DJ. Molecular pathways: microsatellite instability in colorectal cancer: prognostic, predictive, and therapeutic implications. Clin Cancer Res. 2012;18:1506-12.

145. Compton CC. Colorectal carcinoma: diagnostic, prognostic, and molecular features. Mod Pathol. 2003;16:376-88.

146. Lech G, Slotwinski R, Slodkowski M, Krasnodebski IW. Colorectal cancer tumour markers and biomarkers: recent therapeutic advances. World J Gastroenterol. 2016;22:1745-55.

147. Mlecnik B, Bindea G, Angell HK, Maby P, Angelova M, Tougeron D, Church SE, Lafontaine L, Fischer M, Fredriksen T, et al. Integrative analyses of colorectal cancer show immunoscore is a stronger predictor of patient survival than microsatellite instability. Immunity. 2016;44:698-711.

148. Fan G, Zhang K, Yang X, Ding J, Wang Z, Li J. Prognostic value of circulating tumor DNA in patients with colon cancer: systematic review. PLoS One. 2017;12:e0171991.

149. Dienstmann R, Vermeulen L, Guinney J, Kopetz S, Tejpar S, Tabernero J. Consensus molecular subtypes and the evolution of precision medicine in colorectal cancer. Nat Rev Cancer. 2017:17:79-92.

\section{Submit your next manuscript to BioMed Central and we will help you at every step:}

- We accept pre-submission inquiries

- Our selector tool helps you to find the most relevant journal

- We provide round the clock customer support

- Convenient online submission

- Thorough peer review

- Inclusion in PubMed and all major indexing services

- Maximum visibility for your research

Submit your manuscript at www.biomedcentral.com/submit
C) Biomed Central 